\title{
GATOS NO FORNO: MEMÓRIA, IDENTIDADE CULTURAL E IMIGRAÇÃO
}

Leopoldo Comitti UFOP

\section{ABSTRACT}

This essay carries out a reading of writings by immigrants and their descendants. It tries to establish connections to their literary expression, their nationalistic utopia and their ambiguous cultural identity. 
Todorov, em $A$ conquista da América', procura mostrar o relacionamento problemático entre duas civilizaçōes a partir da incomunicabilidade, das diferenças de linguagem e códigos. A leitura de um novo universo passa necessariamente por um processo de tradução, no qual gestos e cenas são interpretados com total indiferença ao conhecimento de um contexto cultural. Sem que o interlocutor tenha condições de interferir no processo, o ato de leitura ganha tons de uma alucinante criação de sentidos e aí o que se manifesta em alto grau é o desejo do leitor.

Na carta de Pero Vaz de Caminha isso fica extremamente explícito, a partir das tentativas de interpretação do escrivão:

Acenderam as tochas e entraram e não fizeram nenhuma menção de cortesia nem de falar ao capitão nem a ninguém, pero um deles pôs o olho no colar do capitão e começou dacenar pera a terra e depois pera o colar como que nos dizia que havia em terra ouro...

Nesse curto trecho, apesar de aparentar uma apreensão da nudez cultural do elemento indígena, observamos o desnudamento do português. Num primeiro momento, Caminha demonstra estranhamento pela inexistência de menções de cortesia, censurando implicitamente o desconhecimento dos padrões europeus de relacionamento humano, pseudamente universais. O segundo momento, no entanto, nos parece mais importante. Ao ler o gesto do índio, o português expõe sua preocupação de conquistador. Num deslocamento metonímico, vai para o primeiro plano o material de que era feito o colar, jamais a peça inteira, o que seria natural. A partir de uma mímica descontextualizada, podemos tecer uma rede extensa de relações e interpretações, a partir dos mais diversos códigos, inclusive o estético, que denunciaria a presença de adornos e elementos decorativos no continente. Para o conquistador, porém, é mais fácil e útil pensar na riqueza, objeto imediato de seu desejo, indiferente que está ao desconhecimento total dos índios aos critérios de atribuição de valor aos metais. Ressalte-se aqui que o discurso de Caminha já prevê e antecipa o modelo de colonização portuguesa, mais voltado, a princípio para o extrativismo, depois para a simples exploração, e sem qualquer preocupação com a fixação de população e desenvolvimento de atividades realmente produtivas.

\section{TODOROV, 1988}

2. CAMINHA, 1989, p. 89
Três séculos depois, os imigrantes alemães, em Santa Catarina, experimentariam dificuldades de comunicação semelhantes às dos portugueses, porém com outro objeto de desejo. A princípio, observamos que, quanto à linguagem, o discurso de ambos os grupos se aproxima bastante, especialmente quando nos deparamos com o depoimento de Antonio Pospissil, citado por Max Heirich Floss, em seu livro Nossos pais:

Numa manhã, chuvosa e brumosa, um dos nossos descobriu de repente uma massa escura no horizonte. Corremos ao comandante que depois de olhar pelo binóculo, disse que aquilo era terra. Enfim terra! A alegria era geral. (...) Canoas haviam rodeado nosso navio, jogando-nos bananas e laranjas. Tinham gosto muito bom. ${ }^{3}$

As semelhanças com a Carta de Caminha são evidentes, especialmente no que diz respeito ao maravilhamento ante a terra avistada. Nota-se, no relato do imigrante, a mesma ânsia do aventureiro diante do desconhecido, especialmente no que diz respeito à linguagem, pontilhada de impressões sensoriais, que, de forma quase sinestésica, procura apreender esse novo universo por meio de uma exacerbação dos sentidos. As descriçōes assemelham-se bastante aos quadros de Eckhout, especialmente às naturezas mortas, nas quais cor e luz se unem para criar uma impressão visual única e extremamente intensa. Como o pintor holandês, também o cronista imigrante carrega nas tintas para nos fornecer principalmente uma sensação gustativa. Se o primeiro contato do português com o Brasil foi um olhar mineral de cobiça, o do imigrante foi um olhar vegetal, de prazer, desejo e satisfação alimentar.

Essa preferência por um código alimentar também se faz presente nos relatos referentes aos primeiros contatos com os índios brasileiros. Em meio a narrativas de massacres, de confissões de medo e de documentação dos aspectos exóticos, o que cresce em importância no depoimento do imigrante Odebrecht é, sem dúvida, a alimentação dos nativos:

Quase nus, eles moram nas infinitas florestas, sem lar definido, levando uma vida nômade e alimentando-se de caça, pesca e frutas silvestres. Encontram-se muitas vezes restos destes alimentos em acampamentos abandonados, freqüentemente também blocos de uma argila gordurosa com rastros de dentes, pederneiras ou pedaços de cogumelos secos, porém nunca uma fijela [sic] ou qualquer objeto de cozinha.

3. POSPISSIL, apud FLOSS, 1961. p. 21.

4. ODEBRECHT, apud ibidem. 
Tais referências ao aspecto alimentar tem suas raízes nas róprias razões que fizeram esses homens deixar a Alemanha. Quase todos camponeses, eles vêm em busca do Eldorado prometido por D. Pedro II porém um Eldorado diferente daquele almejado pelos portugueses do século XVI. Se o conquistador já projetava em sua mente a nova terra, se ia na aventura o paraíso imaginado pelos europeus, o imigrante via e o medo. Se a velha Alemanha era uma possibilidade de vida esvaziada, a América era um vazio a ser preenchido, um desafio de criação. Esse contexto é percebido claramente por Floss, em seus comentários aos depoimentos:

O futuro jazia na obscuridade. O homem tinha que ser forte para tomar a decisão da partida. Emigração alemã porém, é sinal de tomar a docis o homem, seja a necessidade. Seja a profissa que nao alimenta mais o homem, terra gasta que não produz mais o suficiente, seja a vida garantida mas sem possibilidades de avanço, sempre era a necessidade que impelia os homens.

Percebe-se, claramente, nesse discurso, que os objetivos de colonização são absolutamente diversos. Ao alemão, interessava a fixação na terra e, especialmente, a produção, uma vez que a Europa não proporcionava mais a possibilidade de sustento ou ascensão social. A im travessia, para os imigrantes, significava bem mais que um possibilidade de retorno. Era, acima de tudo, abandonar parentes, paisagens, mundo doméstico e conhecido e mergulhar no estranho e imponderável. Era, precisamente, cortar raízes, como bem observa Antonio Pospissil, na conclusão de seu relato:

No terceiro dia, nossas coisas foram descarregadas e todos pudemo desembarcar e eu pude reconhecer os arredores, com bonitas palmeiras desembar que recém-nascido nesta bela terra e não poderia ter escolhido melhor pátria nova...6

O tom quase bíblico do relato sublinha a "visão do paraíso" e ressalta ainda mais o desfecho, com sua declaração de "nascimento". Integrar-se ao Brasil parecia ser, antes de mais nada, buscar uma nova identidade, identidade esta a ser construída a partir da nova condição: não mais um camponês de terras domesticadas e mansas, mas o colonizador,

5. ibidem. p. 15,19 e 21

6. POSPISSIL, apod FLOSS, 1961. p. 21.
No contexto da imigração alemã, a criação dessa nova identidade se apresenta problemática. Isolados numa região até então deserta, os imigrantes se vêem quase sem contato com o restante do país. O Brasil, enquanto pátria, é algo ainda muito distante. Quase que esquecidos pelo Império, e depois pela Velha República, esses novos núcleos de colonização dispersos pelo Paraná, Rio Grande do Sul e, especialmente, Santa Catarina, enfrentam dificuldades em todos os aspectos da vida cotidiana. As promessas do Imperador ficaram todas esquecidas em alguma gaveta burocrática.

Assim, os imigrantes buscam soluções próprias, que resultam sempre na transposição de suas condições anteriores de vida para o Brasil. $\mathrm{Na}$ falta de escolas públicas, criam-se escolas alemãs, nas quais as crianças são alfabetizadas por professores trazidos da Europa em língua alemã. As cartilhas e manuais escolares, além de importadas, são adaptadas às condiçōes locais. Até mesmo Geografia e História do Brasil. Esse isolamento perdura até a década de 30 e só é rompido drasticamente pelo Estado Novo, a partir de práticas autoritárias e xenófobas.

Lausimar Laus, no romance $O$ guarda-roupa alemão ${ }^{7}$, revê criativamente esse período histórico, especialmente focalizando as dificuldades da formação dessa nova identidade. Se os pais, por mais que tenham tentado cortar suas raízes alemãs, ainda mantêm relações estreitas com a cultura de origem, a primeira geração de brasileiros filhos de imigrantes se encontra num vazio. A sensação que temos, ao acompanharmos o percurso das personagens, é de um homem montado sobre o Atlântico: com um pé na Alemanha e outro no Brasil. Ou então de uma gangorra. Se a repressão getulista os atira em direção a uma identidade européia (nesse caso, estreitamente relacionada ao nazismo), o nascimento, a terra e a vivência na América os fazem procurar uma identidade brasileira.

Nitidamente, pesa mais o aspecto vivencial, já que a travessia, simbolicamente, implica numa transformação. Esse novo homem que surge se manifesta no texto como um mediador entre duas culturas, uma de contornos mais urbanos, em processo de industrialização, e outra ainda agrícola e rural; uma fixada e aparentemente ossificada, outra nova e passível de rápidas transformações. Em suma, utilizando aqui uma expressão do código ferroviário, esse homem da primeira geração de filhos de imigrantes 
aparece como uma espécie de guarda-chaves, mediando e tornando possível a passagem de uma via para outra, ao realizar o desvio dos trilhos.

No romance, o ritual de passagem adquire a concretude no guarda-roupa mencionado no título da obra. Como suporte de uma representação simbólica, o móvel acompanha a família Ziegel, refletindo as modificações pelas quais ela passa a partir de sua utilização e alteraçōes de funçōes. Em princípio, trazido da Alemanha para ser efetivamente um guarda-roupa, o móvel acaba, no decorrer do tempo, se tornando um receptáculo de uma multiplicidade de objetos, todos referentes às experiências vivenciais da família. Como interlocutor do narrador, ele espelha uma identidade em transformação, não só pela quantidade de documentos que traz em si, mas também pelo espelho octogonal que ostenta. Metáfora da casa, o armário a acolhe dentro de si e, por sua vez, a casa acolhe o armário como objeto e também como sua representação. Espelho frente a espelho, observamos nesse jogo uma perfeita elisão de qualquer referencial. No universo fechado de imagens, qualquer identidade fica restrita unicamente à moldura e aos movimentos que um espelho ensaia diante do outro. Se os pais preferem a moldura, os filhos se voltam para o movimento, única possibilidade de rompimento desse jogo encantatório.

Não por acaso, o narrador apresenta o guarda-roupa alemão como um receptáculo de vida e morte. Originalmente criado para conter vestimentas, tem suas funções alteradas, como se ele também fosse um corpo que muda de identidade ao trocar de roupa. Como testemunha, e ao mesmo tempo agente de transformações, coloca-se no âmbito do transitório por meio do espelho octogonal, e no âmbito do permanente, por ser moldura, mas também por conter em si o registro, a memória dos ancestrais e, principalmente, a ossada de Hilda, guardada na gaveta após esta ser sacrificada por transgredir a tradição.

Essas fricções entre imigrantes e seus filhos ganham acolhida principalmente na linguagem cotidiana e nas frases de efeito reiteradas nas relaçōes familiares. Exemplo disso é a pergunta formulada pelas velhas senhoras alemãs, quando algum neto se declara brasileiro: "Por acaso, gato que nasce no forno é biscoito?" Por trás desse recurso de convencimento aparentemente banal, com nítido objetivo de desconsertar e elidir uma resposta, já que a proposição se coloca no âmbito do absurdo, há toda uma teia de sentidos não enunciados. São sentidos que bordejam o vazio, que circundam o silêncio do interlocutor e mascaram uma identidade cultural problemática.
Apesar de formu Pisponível em http:///www.letras.ufmg.br/poslit enunciado nitidamente assertivo, uma vez que admite uma única resposta: não. Numa proposição paralógica, o enunciado cria a interseç̧ão de dois campos semânticos distintos, claramente privilegiando o primeiro. Com tal formulação, procura-se eclipsar da discussão qualquer possibilidade de se relacionar a questão da identidade a fatores culturais. Frisa-se, a partir da imagem do gato, o elemento racial. A diferença, então, passa necessariamente pelo biológico e a proposição insere-se no contexto dos discursos autoritários; no caso alemão, do nazista.

Em oposição, o segundo campo semântico passa a ser totalmente desqualificado, apesar de apontar para um código alimentar, tão caro aos imigrantes.

A razão da desqualificação é, sem dúvida, o fato deste se relacionar ao vivencial $e$ independer de fatores inatos. Ser brasileiro, para esse grupo de resistência ao autoritarismo do Estado Novo, é, necessariamente, se identificar com o biscoito. Ou seja, abdicar de um essencialismo racial, de uma tradição herdada, e reconhecer-se nascido na terra, mas não pronto e sim em estado de transformação: uma transformação que se dá principalmente pela construção de novas identidades, não mais radicais e ancoradas em fatores biológicos e políticos, mas mutante e dialógica.

Esse dialogismo, inerente à polimorfa sociedade brasileira, recebe a adesão das gerações subseqüentes de filhos de imigrantes. Em Aleluia Gretchen, filme de Sílvio Back, a saga de uma família alemã, em tudo aparentada daquela mostrada por Lausimar Laus, adquire um novo tratamento. No romance, centrado nos anos 30, a miscigenação e a integração forçada culminam com um crime e potencializam a angústia. No filme, há uma recusa evidente a um tom épico ou trágico. A ação, conduzida de forma fragmentária, quase delirante, passa pela tensão do Estado Novo, da $2^{2}$ Guerra Mundial e espraia-se até os anos 60 e 70 , numa espécie de anti-clímax festivo: a câmera abre para um plano geral no momento em que uma festa familiar se transforma em Carnaval.

A opção pelo dialógico/carnavalesco se concretiza, assim, pelo movimento da câmera que, ao invés de se fechar em close, abre-se para a diversidade. Uma opção pelo Biscoito. Rejeita-se a nobreza e universalidade do gato, para se acatar a transitoriedade da culinária cotidiana. 


\section{FICÇÃO QUE SE REALIZA: O BRASIL URBANO NA OBRA DE SÉRGIO SANT'ANNA}

Luis Alberto Brandão Santos $U F M G$ close dialogue with the contemporary questions. One of these questions is the emergence of a chaotic Brazil, basically urban. This essay aims at approaching Sant'Anna's urban Brazil, discussing the relationship between recognition and uncertainty in reality/language articulation. 